\title{
Use of smartphone applications to improve quality of bowel preparation for colonoscopy: a systematic review and meta- analysis
}

\section{(ㄷ)(우우}

\author{
Authors \\ Madhav Desai, Venkat Nutalapati, Ajay Bansal, Daniel Buckles, John Bonino, Mojtaba Olyaee, Amit Rastogi
}

\section{Institution}

Department of Gastroenterology and Hepatology, University of Kansas School of Medicine, Kansas City, KS, USA

submitted 20.7.2018

accepted after revision 27.9.2018

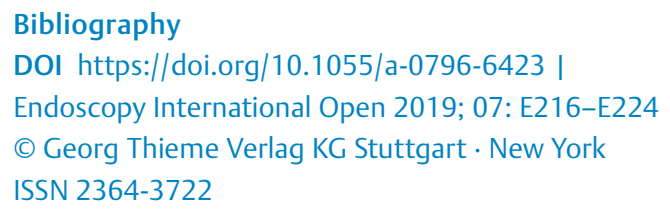

Corresponding author

Amit Rastogi, MD, University of Kansas Medical Center, 3901 Rainbow Blvd, Kansas City, KS, USA

Fax: +1-281-569-9320

arastogi@kumc.edu

丹 Supplement 1-6

Online content viewable at:

https://doi.org/10.1055/a-0796-6423

\section{ABSTRACT}

Introduction Smartphone-based applications (apps) have been used to improve the quality of bowel preparation (prep) but the success rates have been variable. We have performed a systematic review and meta-analysis to evaluate the impact of smartphone apps on bowel preparation. Methods Electronic databases (MEDLINE, Embase, CINAHL and Cochrane) were reviewed for eligible studies of smartphone apps versus standard education before colonoscopy. The following outcomes were analyzed: pooled rate of adequacy of bowel prep among both arms and Boston bowel preparation score (BBPS) when reported. Pooled analysis was reported as odds ratio (OR) or mean difference in random effect model with Review Manager 5.3 ( $P \leq 0.05$ for statistical significance).

Results Six studies were eligible with smartphone app (810 patients) vs. standard education (855 patients, control group) for bowel prep. The smartphone app group had a higher proportion of adequate bowel prep compared to the control group: $87.5 \%$ vs $77.5 \%$ (five studies), pooled OR $2.67 ; 95 \% \mathrm{Cl} 1.00-7.13$ with $P=0.05$. There was substantial heterogeneity in studies with $R^{2}=78 \%$. When analysis was limited to randomized controlled trials (RCTs), smartphone app users had a numerically higher rate of bowel cleansing: $87.1 \%$ vs $76.9 \%$; however, pooled OR was not statistically significant (OR 2.66, $95 \% \mathrm{Cl} 0.92-7.69, P=$ $0.07)$. When studies using BBPS were evaluated $(n=3)$, smartphone app users had higher mean scores (better bowel prep) with a mean difference of $0.9(95 \% \mathrm{Cl} 0.5-1.3)$, which was statistically significant $(P<0.01)$.

Conclusion The smartphone app is a novel educational tool that can assist in achieving adequate and better bowel cleansing before colonoscopy.

\section{Introduction}

Colon cancer is the 4th most common cancer in the United States and the 3rd leading cause of cancer-related deaths in men and women in the United States [1]. Colonoscopy is the preferred screening method for colorectal cancer in the United States. As most colon cancers arise from adenomas, screening and surveillance colonoscopy are performed primarily to detect these premalignant polyps and to remove them, in order to prevent the future possibility of transformation to cancer. Bowel preparation (bowel prep) for colonoscopy is crucial for the per- formance of a successful procedure aiding good visualization and detection of lesions. Adequacy of bowel prep is an important quality indicator of colonoscopy [2-4]. Detection of polyps has been shown to correlate with bowel prep quality. Inadequate bowel prep has been associated with longer procedure time, complexity, risk of complications, risk of missing adenomas, and increased costs as repeat exam is warranted $[2,4]$.

Bowel preparation or cleansing depends on several factors, the major ones being type of solution used, adherence to split dosing, and patient comfort. Data is scarce on incomplete or failed colonoscopies. Previous studies $[5,6]$ report rates of 
incomplete or inadequate bowel cleansing to be around $20-30$ $\%$ on average, leading to recommendation of an earlier repeat exam. Repeat exam subjects the patients to additional discomfort, risk of sedation and procedure as well as increasing the overall health care expenditure.

Patient education is quintessential to successful bowel cleansing. Various educational means have been used including audiovisual aids to assist patients with bowel preparation [78]. Smartphone-based applications (apps) have been studied as well, to understand their impact in achieving satisfactory bowel preparation [9-11]. Smartphone apps are software platforms for smartphones that can be easily used for patient education. The United States is one the largest smartphone markets in the world with one of the highest smartphone penetration rates worldwide. In the year 2017 , almost $68 \%$ of the US population was using a smartphone [12]. These rates are increasing rapidly. Smartphone-based applications have been used for health, fitness, and other medical conditions such as diabetes management [13-15]. Interactive application use on a smartphone to enhance bowel cleansing is an attractive, convenient, and user friendly option compared to formal nurse directed education in person or on the phone. A previous meta-analysis attempted to assess the impact of audiovisual aids to improve bowel cleansing for colonoscopy [7]; however, only one study included in this used smartphone-based applications. Since then, other studies have been published reporting the efficacy of smartphone use for bowel preparation compared to controls (standard patient education) [10-11,16-18]. However, results have been conflicting and no pooled analysis has previously been attempted to assess the impact of such methods.

We have performed a systematic review and meta-analysis to evaluate the impact of smartphone apps on bowel preparation compared to standard patient education. Our aim was to compare pooled rates of adequate bowel prep between the two groups.

\section{Methods}

\section{Search strategy}

The meta-analysis was performed according to PRISMA statement (Preferred reporting items for systematic reviews and meta-analysis) [19]. A comprehensive electronic literature search was conducted in PubMed/MEDLINE, EMBASE, CINAHL, and Cochrane databases to identify studies that assessed use of "smartphone app" to improve bowel preparation quality (bowel cleansing) compared to control or standard of care from the beginning of indexing for each database to 10 January 2018. Bibliographic reviews of selected articles and major gastrointestinal proceedings were examined as secondary sources for full-length articles of studies on the use of the smartphone app for colonoscopy. A literature search was performed and verified by two authors (M.D. and V.N.) with no restriction in language. The search for studies of relevance was performed using the following text words and corresponding Medical Subject Heading/Emtree terms when possible: "colonoscopy” AND "smartphone app" OR "phone application" OR "audiovisual aid”. Detailed search terms are shown in Supplement 1.

\section{Eligibility criteria}

Two reviewers (M.D. and V. N.) independently evaluated all of the studies retrieved according to the eligibility criteria and any disagreement was resolved by consensus. Studies were included if they met all of the following criteria: (1) comparative studies (either prospective or retrospective) with control group comparing patients who used a smartphone app for bowel preparation and those who did not; (2) primary outcome reporting the adequacy of bowel prep (adequate vs not adequate bowel prep); (3) information on some form of bowel preparation scale, e. g. Boston Bowel Preparation Scale (BBPS) or other scales to rate the bowel prep quality. We excluded articles if there was no documentation on adequacy of bowel prep or bowel prep scale was not reported.

\section{Data extraction and quality assessment}

Data were extracted from the selected studies independently and verified for accuracy by the other reviewer. Any disagreement was resolved by consensus. The following data were extracted from each study: first author, year of publication, study design, number of participants, age, gender, indication for colonoscopy, intervention, type of bowel prep, success or adequacy of bowel prep, Boston Bowel Preparation Scale (BBPS) scores (whole colon and for right colon alone), if other scales used then respective name of scale and scores among both groups, previous experience with colonoscopy. We also obtained data on satisfaction scales and score (visual analog scale) and adherence scales, when reported.

Study quality was assessed using Cochranes's risk of bias tool [20] for randomized controlled trials (RCTs) and Newcastle - Ottawa scale [21] (score $\geq 7$ considered high quality) for non-RCTs (Supplements 2 and $\mathbf{3}$ ).

\section{Outcomes}

Primary outcome was pooled proportion of patients with adequate bowel prep. Adequacy of bowel prep (adequate being either excellent or good per Aronchick scale) was the most common outcome reported among studies and more clinically relevant, therefore selected as the primary outcome of this metaanalysis [22]. The Aronchick scale defines the various grades of bowel prep as: excellent (small amount of clear liquid with clear mucosa seen; more than 95\% mucosa seen), good (small amount of turbid fluid without feces not interfering with examination; more than $90 \%$ mucosa seen), fair (moderate amount of stool that can be cleared with suctioning permitting adequate evaluation of entire colonic mucosa; more than $90 \%$ mucosa seen), inadequate (inadequate but examination completed; enough feces or turbid fluid to prevent a reliable examination; less than $90 \%$ mucosa seen), poor (repreparation required; large amount of fecal residue precludes a complete examination). Adequate bowel prep was calculated as percentage of patients with excellent or optimal (good) bowel prep among the total participants in each group in this pooled analysis. BBPS was not reported consistently among all of the studies and therefore studied as a secondary outcome. For BBPS, 
mean values of the scale were given among participants, rather than the percentage of participants with adequate bowel prep.

Secondary outcomes were: pooled mean score of BBPS, pooled mean score of Ottawa scale, rate of previous experience with bowel prep and if so, pooled mean score of bowel preparation scale scores. We also performed sensitivity analysis to detect any discrepancies in primary outcome.

\section{Statistical analysis}

The measure of effect of interest was the odds ratio (OR) - an estimate of the chances of success (achieving adequate bowel preparation) of the intervention compared to control. The primary outcome of interest, the pooled rate of adequacy of bowel prep, was calculated with $95 \%$ confidence intervals with a random effects model if heterogeneity was identified. Similarly, pooled mean difference was calculated using the inverse variance method for outcomes of BBPS and other bowel prep scales when outcomes were available in the form of mean scores or as continuous variables. Corresponding forest plots were constructed for pooled estimates of these outcomes and weights of individual studies are represented by size of individual squares. All meta-analytic computations, including the estimates and $95 \%$ confidence intervals $(\mathrm{Cl})$ for pooled rates as well as the measurement of heterogeneity (measured as $R^{2}$ statistics) were performed using Review Manager v5.3 statistical software (The Nordic Cochrane Centre, Copenhagen, Denmark). $I^{2}$-values of $0-40 \%, 30-60 \%, 50-90 \%$, and $75-100 \%$ were indicated as low, moderate, substantial, and considerable heterogeneity, respectively. $P \leq 0.05$ was considered statistically significant for all outcomes. Publication bias was analyzed with Review Manager (RevMan) software Version 5.3 using funnel plots [23].

\section{Results}

\section{Studies and patient characteristics}

Study selection and the screening process are shown in $\mathbf{F i g .} \mathbf{1}$. A literature search in major databases and a secondary search identified a total of 520 records. After removing duplicates and non-relevant records, there were 147 citations. Of these, abstract form only, case series/studies, review articles, editorials, and uncontrolled studies were removed, i. e. 13 full text articles were reviewed. Of these, a total of six studies were found eligible for inclusion. Four of them were randomized controlled trials $[9-11,18]$, one was a nonrandomized prospective feasibility trial [16] with control arm and one was a prospective feasibility study with matched controls from outpatient colonoscopy [17]. The studies used different smartphone apps designed for that specific study. One study used a mobile application based on the "chat" function on social media [18].

To the knowledge of the study authors, out of the six studies, none of the study apps are currently in commercial use. Back et al. (2018) [11] provided information that was freely accessible to study participants to be downloaded in the Korean language (by a web link) but no commercially available software name or information was provided. Lorenzo-Zuniga et al. (2015) [9] prepared the app for free download by users and

\section{0 records found}

- Pubmed/Medline (129)

- Embase (361)

- Cochrane (4)

- CINAHL (3)

- Secondary search including bibliographic review of selected articles and major GI proceedings (23)

\section{7 records after duplicates removed}

13 full text articles reviewed

134 records removed (abstract form only, review, case series, uncontrolled design)

\section{series, uncontrolled design)}

6 studies found eligible

- Fig. 1 Study flow diagram.

participants (only Spanish language users) using iOS (or other systems) and which was easily accessible by a quick response code. Cho et al. (2017) [16] also provided information to download the app for free for Android systems by a quick response code but this was also not commercially available as software. The authors of the current study used the quick response codes provided in the manuscript, but we were not able to download this software as it was not currently available. Walter et al. (2017) [17] developed their app for Android systems and called it "The Colonoscopy Preparation App (ColoprAPP)" which was provided to the participants through cloud software. However, this was not commercially or freely available. Sharara et al. (2017) [10] prepared the app solely for the study and it was not commercially available but this was provided to participants with Android and iOS systems. Kang et al. (2016) [18] used the "WeChat" social media app to deliver information (or reminders) with regard to bowel prep, however, whether this is commercially available or not is not clear. Probably this was intended for the purpose of the study and information was only sent to a specialized group of participants who were connected to a common account in WeChat. So, this was not applicable or generalizable outside of WeChat users.

There were a total of 810 patients who used smartphone apps for bowel prep and 855 patients who were given standard education including patient instructions (control) for bowel preparation for colonoscopy. The average age of patients in the smartphone app user group was 47.7 years and $53 \%$ were male. The average age in the control group was 49.9 years and $49 \%$ were male. Study quality assessment with the Cochrane risk of bias tool and the Newcastle-Ottawa scale did not show any major source of bias in the included studies. These are shown, respectively, in Supplements 2 and 3. Study and patient characteristics are shown in $>$ Table 1. 
- Table 1 Study and patient characteristics among those who used smartphone-based applications versus those who did not (control).

\begin{tabular}{|c|c|c|c|c|c|c|}
\hline & Back et al. [11] & Cho et al. [16] & $\begin{array}{l}\text { Walter et al. } \\
\text { [17] }\end{array}$ & $\begin{array}{l}\text { Sharara et al. } \\
{[10]}\end{array}$ & $\begin{array}{l}\text { Lorenzo-Zuniga } \\
\text { et al. [9] }\end{array}$ & Kang et al. [18] \\
\hline Year & 2017 & 2017 & 2017 & 2017 & 2015 & 2016 \\
\hline Type & $\begin{array}{l}\text { Prospective, } \\
\text { endoscopist- } \\
\text { blinded, ran- } \\
\text { domized, con- } \\
\text { trolled study }\end{array}$ & $\begin{array}{l}\text { Prospective } \\
\text { controlled trial } \\
\text { [an app devel- } \\
\text { opment phase } \\
\text { and a validation } \\
\text { study] }\end{array}$ & $\begin{array}{l}\text { Prospective fea- } \\
\text { sibility study }\end{array}$ & $\mathrm{RCT}$ & $\begin{array}{l}\text { Prospective, } \\
\text { endoscopist- } \\
\text { blinded, ran- } \\
\text { domized, con- } \\
\text { trolled trial }\end{array}$ & RCT \\
\hline Intervention & $\begin{array}{l}\text { Audiovisual re- } \\
\text { education } \\
\text { through smart- } \\
\text { phone app be- } \\
\text { fore colonosco- } \\
\text { py }\end{array}$ & $\begin{array}{l}\text { Designed } \\
\text { smartphone app }\end{array}$ & Coloprapp & $\begin{array}{l}\text { Smartphone } \\
\text { app }\end{array}$ & $\begin{array}{l}\text { Smartphone } \\
\text { app }\end{array}$ & $\begin{array}{l}\text { Wechat (a wide- } \\
\text { ly used mobile } \\
\text { social media } \\
\text { app): informa- } \\
\text { tion delivered } \\
\text { using this social } \\
\text { media app to } \\
\text { people who } \\
\text { used the social } \\
\text { media app }\end{array}$ \\
\hline \multicolumn{7}{|l|}{ Smartphone app } \\
\hline Patients, n & 139 & 71 & 25 & 80 & 108 & 387 \\
\hline Males, n & $77 / 139$ & $42 / 71$ & $11 / 25$ & $52 / 80$ & $48 / 108$ & $202 / 387$ \\
\hline Age, mean $\pm S D$ & $55.4 \pm 12.8$ & $42.3 \pm 10.3$ & 44.1 & $52 \pm 13$ & $48.3 \pm 13.5$ & $44.4 \pm 13.2$ \\
\hline $\begin{array}{l}\text { Adequate bowel } \\
\text { prep }\end{array}$ & $134 / 139$ & NA & $25 / 25$ & $62 / 80$ & $108 / 108$ & $318 / 387$ \\
\hline BBPS & $7.53 \pm 1.38$ & $7.70 \pm 1.1$ & $8.1 \pm 0.3$ & $\begin{array}{l}\text { Ottawa: } 6.40 \pm \\
1.95 \text {, Chicago: } \\
32.08 \pm 4.970\end{array}$ & HCS: $17.1 \pm 3.2$ & Ottawa: $3.6 \pm 1.7$ \\
\hline $\begin{array}{l}\text { Adherence scale } \\
\text { for taking pur- } \\
\text { gative, \% }\end{array}$ & 95.00 & NA & NA & 97.50 & NA & 90.40 \\
\hline $\begin{array}{l}\text { Previous experi- } \\
\text { ence with colo- } \\
\text { noscopy }\end{array}$ & 53 & 34 & 11 & NA & 31 & 91 \\
\hline $\begin{array}{l}\text { BBPS after tak- } \\
\text { ing out pts with } \\
\text { prior colonosco- } \\
\text { py: App }\end{array}$ & & $\begin{array}{l}\mathrm{N}=37,17 \mathrm{M} / \\
20 \mathrm{~F}, \mathrm{BBPS}= \\
7.73 \pm 1.3\end{array}$ & NA & NA & NA & NA \\
\hline BBPS right colon & NA & $2.42 \pm 0.5$ & $2.5 \pm 0.13$ & NA & NA & $\begin{array}{l}\text { Ottawa scale } \\
\text { given }\end{array}$ \\
\hline \multicolumn{7}{|l|}{ Control } \\
\hline Patients, N & 144 & 71 & 25 & 80 & 152 & 383 \\
\hline Males, N & $81 / 144$ & $42 / 71$ & $11 / 25$ & $37 / 80$ & $60 / 152$ & $191 / 383$ \\
\hline Age, mean $\pm S D$ & $57.6 \pm 13.1$ & $44.8 \pm 5.4$ & 44.1 & $55 \pm 12$ & $52.5 \pm 14$ & $45.5 \pm 13$ \\
\hline Success & $106 / 144$ & NA & $24 / 25$ & $66 / 80$ & $146 / 152$ & $266 / 383$ \\
\hline BBPS & $6.29 \pm 1.83$ & $7.24 \pm 0.8$ & $7.1 \pm 0.4$ & $\begin{array}{l}\text { Ottawa: } 6.43 \pm \\
1.84 \text {, Chicago: } \\
32.61 \pm 3.59\end{array}$ & HCS: $16.5 \pm 3.1$ & Ottawa: $4.5 \pm 1.8$ \\
\hline $\begin{array}{l}\text { AS (Adherence), } \\
\%\end{array}$ & 82 & NA & NA & 96.20 & NA & 82.70 \\
\hline
\end{tabular}


- Table 1 (Continuation)

\begin{tabular}{|c|c|c|c|c|c|c|}
\hline & Back et al. [11] & Cho et al. [16] & $\begin{array}{l}\text { Walter et al. } \\
\text { [17] }\end{array}$ & $\begin{array}{l}\text { Sharara et al. } \\
{[10]}\end{array}$ & $\begin{array}{l}\text { Lorenzo-Zuniga } \\
\text { et al. [9] }\end{array}$ & Kang et al. [18] \\
\hline $\begin{array}{l}\text { VAS (Visual } \\
\text { analog scale) }\end{array}$ & $7.90 \pm 1.94$ & NA & NA & $\begin{array}{l}\text { Given but not } \\
\text { compared } \\
\text { properly }\end{array}$ & NA & NA \\
\hline $\begin{array}{l}\text { Previous experi- } \\
\text { ence with colo- } \\
\text { noscopy }\end{array}$ & 46 & 19 & 11 & NA & 64 & 112 \\
\hline $\begin{array}{l}\text { BBPS after tak- } \\
\text { ing out pts with } \\
\text { prior colonosco- } \\
\text { py }\end{array}$ & NA & $\begin{array}{l}N=37,30 \mathrm{M} / 7 \mathrm{~F}, \\
\mathrm{BBPS}=7.16 \pm \\
0.8\end{array}$ & NA & NA & NA & NA \\
\hline BBPS right colon & NA & $2.18 \pm 0.4$ & $2.3 \pm 0.11$ & NA & HCS given & $\begin{array}{l}\text { Ottawa Scale } \\
\text { given }\end{array}$ \\
\hline
\end{tabular}

\section{Primary outcome}

There were five studies available for analysis of adequate bowel preparation. The smartphone app user group had a higher proportion of adequate bowel preparation compared to the control group: $87.5 \%$ vs $77.5 \%$. Pooled OR was 2.67 with $95 \% \mathrm{Cl}$ $1.00-7.13$. Pooled outcome was trending towards significance $(P=0.05)$. A forest plot using pooled data from both groups is shown in $>$ Fig. 2. There was substantial heterogeneity in studies with $R^{2}=78 \%$.

\section{Secondary outcomes}

When studies using BBPS were evaluated $(n=3)$, smartphone app users had higher mean scores (better bowel prep) with a mean difference of $0.9(95 \% \mathrm{Cl} ; 0.5-1.3)$, that was statistically significant $(P<0.01)$. This is demonstrated in > Fig. 3 .

BBPS in the right colon was assessed in two studies (Supplement 4). Smartphone app users had better BBPS in the right coIon with a pooled mean difference of $0.21 ; 95 \% \mathrm{Cl} 0.15-0.27$ that was statistically significant $(P<0.01)$. The Ottawa scale was used in two studies (Supplement 5) and there was no difference in both groups and the pooled mean difference was0.51 with $95 \% \mathrm{Cl}-1.36$ to 0.34 . Results were not statistically significant $(P=0.24)$.

There were $30.1 \%$ of patients who had previous exposure to bowel prep in the smartphone app group (220/730), while there were $32.5 \%$ of patients who had previous exposure to bowel prep in the control group (252/775); however, only one study assessed BBPS after excluding patients who had previous exposure to bowel prep (smartphone BBPS $=7.73 \pm 1.3$ vs controls $B B P S=7.16 \pm 0.8)$ [16]. BBPS was better in smartphone app users compared to controls $(P=0.031)$.

\section{Sensitivity analysis}

When analysis was limited to randomized controlled trials (RCTs) alone ( $\triangleright$ Fig. 4 ), smartphone app users had a numerically higher rate of adequate bowel cleansing: $87.1 \%$ vs $76.9 \%$; however, this was trending but still not statistically significant $(P=$ 0.07). Pooled OR was 2.66 with $95 \% \mathrm{Cl} 0.92-7.69, P=0.07$. When the study by Sharara et al. [10] was excluded (as explained in the Discussion), there was a statistically significant difference seen with pooled OR 4.66, $95 \% \mathrm{Cl} 1.21-17.88 ; P=$ 0.03 , with the smartphone app users achieving a higher proportion of adequate bowel cleansing compared to controls.

When analysis was performed excluding the study by Kang et al. [18] that used the social media mobile application (WeChat), the study results were not statistically significantly different (pooled OR 3.53, $95 \% \mathrm{Cl} 0.42-29.58, P=0.24$ ).

\section{Publication bias}

There were only five studies available for assessment of publication bias for primary outcome. A funnel plot (Supplement 6) showed that there was no major publication bias; however, one study [10] lay outside the plot.

\section{Discussion}

The success of colonoscopy is linked closely to the adequacy of bowel prep [2]. Inadequate colon preparation is associated with reduced adenoma detection rates [24] Despite its importance, around $20-25 \%$ of bowel preparations in clinical practice remain inadequate [25]. Modifiable risk factors that can be crucial to ensure an adequate prep include patient guidance and education [26]. We wanted to evaluate the evidence with regard to the impact of education via smartphone app on bowel preparation. We performed pooled analysis of 1665 patients undergoing colonoscopy and found that using a smartphonebased app was effective in improving bowel cleansing. Our 


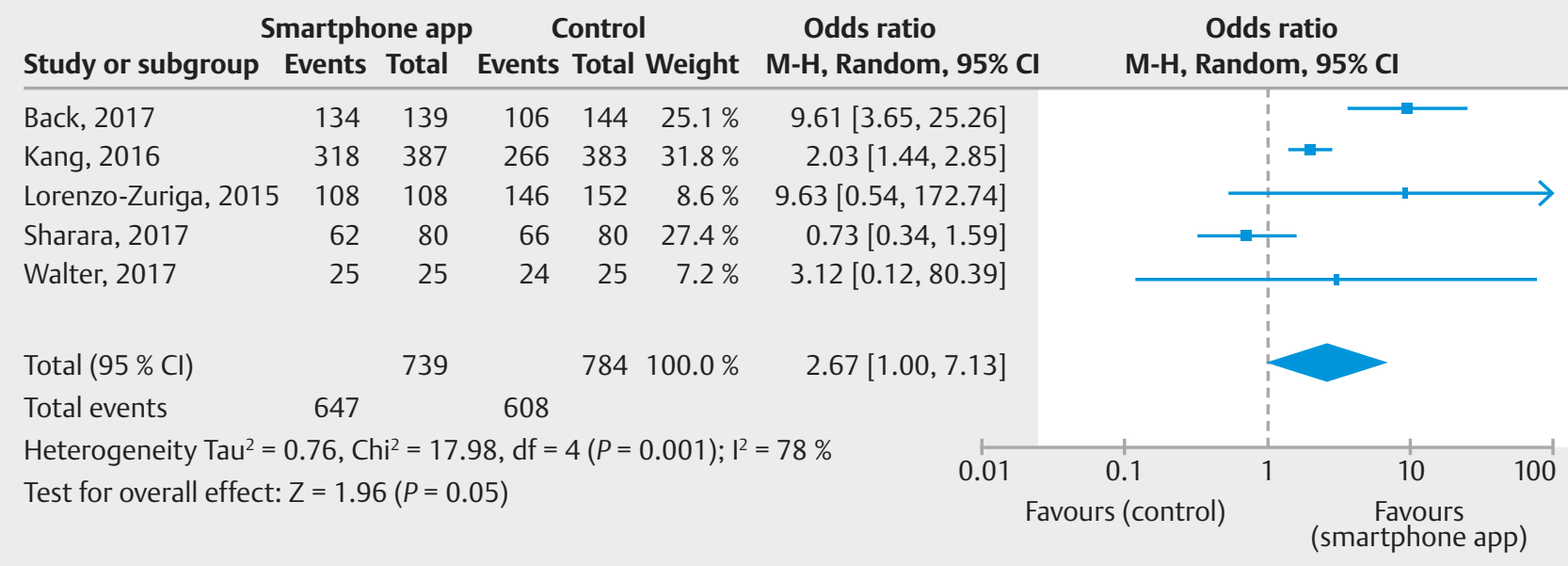

- Fig. 2 Adequate bowel prep among both groups (all studies).

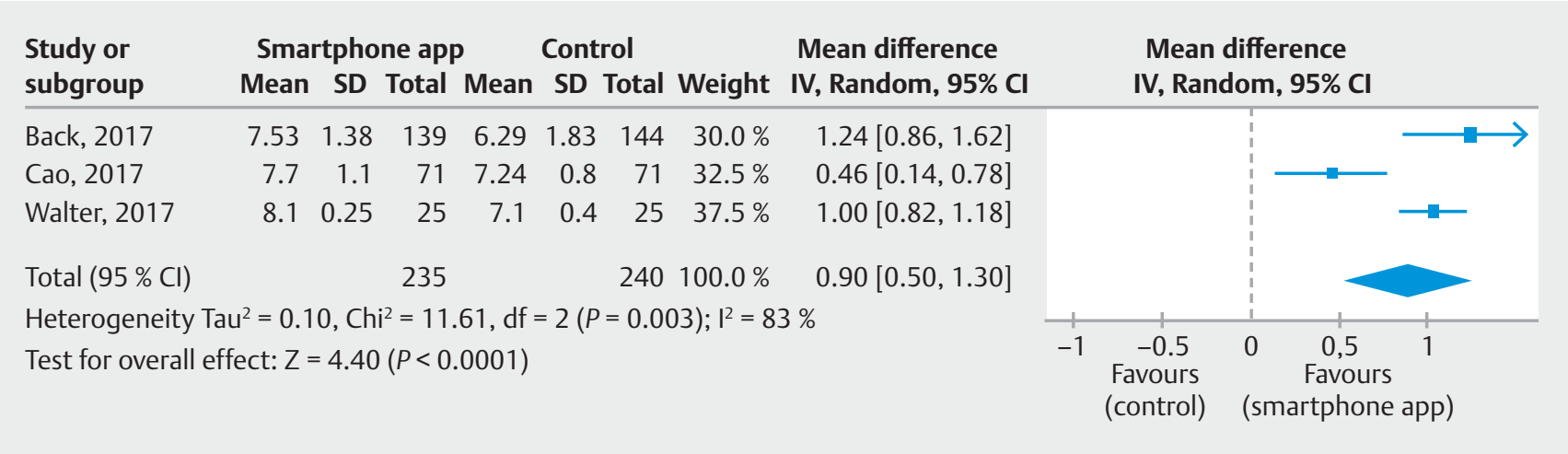

- Fig. 3 Boston Bowel Preparation Score among both groups.

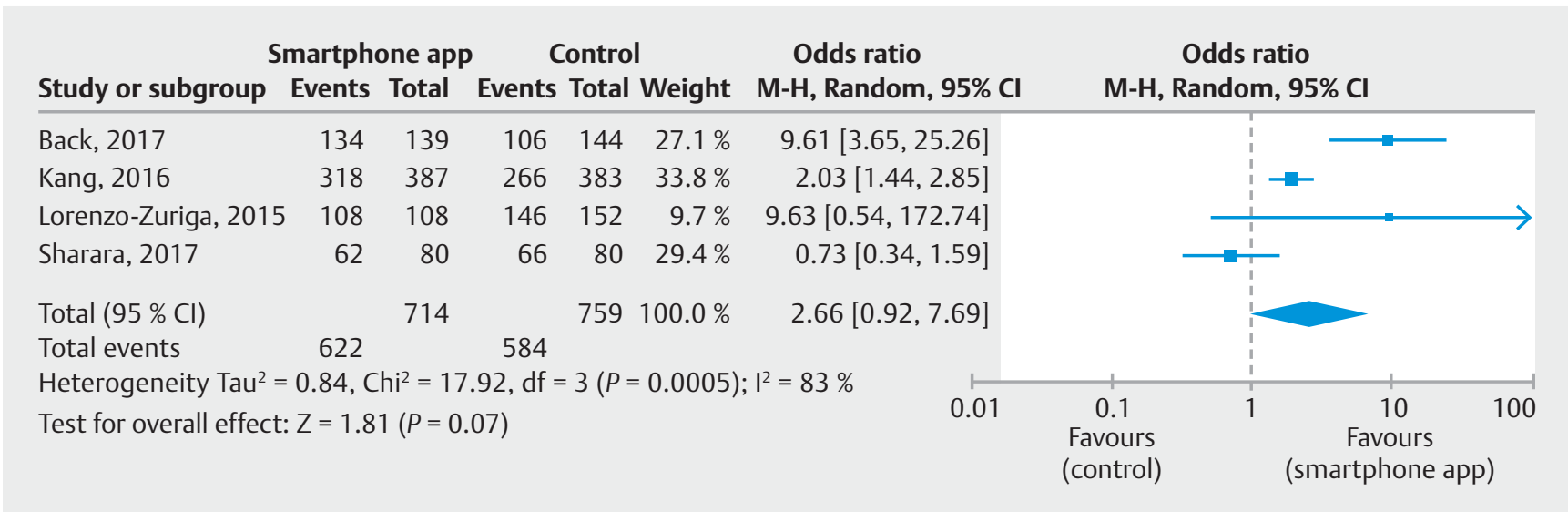

- Fig. 4 Adequate bowel prep among both groups (only RCTs).

meta-analysis showed that a $10 \%$ higher adequate bowel preparation was achieved in the smartphone app group compared with the standard patient instruction group alone. Patients using the smartphone app had higher bowel preparation scale scores compared to controls. There was substantial heteroge- neity in primary outcome among inclusion studies that likely stems from the fact that there was no standard smartphone app that was used among the studies in addition to methodological and clinical heterogeneity among included studies. 
The pooled rate of satisfactory bowel prep (adequate or higher) was trending towards significance. We believe that due to how close the $P$ value is to the significance level, one could very easily state that there is no significant difference between the groups, depending on how statistical significance is defined in this meta-analysis (i.e. less than 0.05 vs. less than/equal to 0.05). On this note, it is likely that more definitive conclusions could have been drawn with regard to the impact of smartphone applications if more studies were available in the literature that could have been included in the meta-analysis. We were able to study other important parameters, pooled rates of BBPS and Ottawa scores from individual studies that also provided us meaningful results rather than mere adequacy rate of bowel prep that is prone to subjective variation and bias.

The studies included were heterogeneous in terms of study design, study population, methodology and most importantly, type of bowel prep as well as type of smartphone application used. Kang et al. [18] used WeChat which is a multipurpose messaging and social media application. However, since the smartphone was primarily used in this study to access WeChat (as opposed to use of separate smartphone-based application in other studies), we incorporated this study in the analysis. It is unclear if use of social media-related apps would have different results compared to smartphone only apps. We performed analysis excluding this study and the results were not different.

The study by Sharara et al. [10] was performed in a tertiary facility and the majority of patients were smartphone users and educated (>50\%). There was no significant difference between adequacy of bowel prep among both groups, however, there was higher patient satisfaction and bowel prep scale scores. Therefore, we performed a sensitivity analysis. After excluding Sharara et al., we found a statistically significant difference in terms of adequate bowel prep in smartphone users compared to controls.

Interventions in the form of simple cards with photographs and text explaining the rationale for bowel preparation have often failed to improve the quality of bowel preparation for colonoscopy [9,27]. However, other studies using visual aids or an educational video, as interventions, have shown a positive effect on quality of bowel preparation $[28,29]$. The use of telephone and mobile messages to enhance education on diet restrictions and bowel preparation and serve as reminders have also led to improvements in bowel preparation [30,31]. These results indicate that education by more interactive audiovisual methods may be needed to improve bowel cleansing. A smartphone app is another way of accomplishing that by displaying text instructions, visual aids, and alerts to the patient with regard to the diet restrictions required, a reminder to start the prep as well as the timing of the split dosing.

With the increasing use of smartphones, apps for bowel prep have the advantage of delivering information in a more user friendly format than some of the other educational methods. Another advantage is the use of automatic alerts, reminders, and notifications as well as the ability to go back to review the instructions about the bowel prep. The time interval between a scheduled colonoscopy and the initial delivery of instructions about bowel prep is often quite long [32]. As a result, patients can easily forget the essential and pertinent instructions and can also misplace any written instructions that were provided at the initial contact. Here is where the smartphone apps or mobile social media apps have an edge, as these will always be available to the patient along with the ability to serve reminders.

There can however also be impediments to the implementation of smartphone apps for bowel cleansing. It requires a smartphone with a service network that may not be available or accessible to all. Smartphones may have a lower penetration in developing countries and possibly in uninsured populations in developed countries. Patients may not be familiar with social media or smartphone apps, and they may need assistance to navigate these making it more tedious and cumbersome than other simpler ways of education. There is a lack of a standardized smartphone app that is widely available for use and in use. Several different apps were used in the studies included in this meta-analysis and probably contributed to the clinical heterogeneity.

Even though we were unable to analyze the data collectively, patients using a smartphone app had a higher satisfaction score in all of the studies. This was evaluated either through a VAS (visual analog scale) or a separate questionnaire created by the study authors. Higher satisfaction and adherence scores in smartphone app users compared to controls may correlate with a better bowel prep experience. Even though study results are showing no difference in terms of statistical significance, higher satisfaction observed with smartphone app-based instructions may be a helpful factor in compliance with the prep and also when repeat colonoscopy is needed. Improved adherence is an important parameter that unfortunately could not be assessed in this analysis due to differing scales used among the studies included. Another factor was detection of a higher number of adenomas (ADR) in smartphone app users. Higher ADR detection was reported in smartphone app users compared to controls ( $18.6 \%$ vs $12.0 \%, P=0.012$ ) which supports the fact that better prep quality improves $\operatorname{ADR}$ detection $[4,18]$. Unfortunately, other studies did not report ADR separately and we were not able to analyze this outcome for further assessment. Another important parameter was bowel cleansing in the right colon and its potential impact on adenoma detection in this region. BBPS of the right colon, although reported in only two studies, was higher in smartphone users compared to controls $[16,17]$.

This meta-analysis has a few limitations. First, there was no standardized universal smartphone app available and the studies included used different smartphone apps. Those apps varied in overall appearance, user-friendliness, alerts, notifications, and reminder functions as well as methods of patient education. In the absence of any commonly available app, it is difficult to draw definitive conclusions with regard to the features of an ideal smartphone app for bowel preparation. Despite this, the results of this analysis provide some sense of the efficacy of using a phone app in improving bowel prep quality. This is an attractive method to improve the quality of the bowel prep and should be investigated further given the rates of poor quality bowel prep in the US and a high rate of smart- 
phone use. Second, the studies used different scales for grading the adequacy of bowel cleansing. Only three studies used the standardized BBPS. Although, primary outcome was the proportion of patients with adequate prep, we believe that using a standard format such as BBPS or Aronchik scale would provide more objective and reliable evidence that could be compared and synthesized together. Third, possessing a smartphone and using it may correlate with socioeconomic status which by itself can impact quality of colon prep and may be a confounding factor $[33,34]$. Therefore, the results of this meta-analysis are not generalizable, especially to populations with a lower penetration of smartphones. Other methods to improve bowel preparation would be needed and explored in those subsets of patients. Health-related literacy is closely linked to adequate bowel prep [35] and smartphone app use, and unfortunately could not be evaluated in this analysis.

In conclusion, use of a smartphone-based app improves bowel preparation and possibly patient satisfaction. This is an attractive option to improve the quality of bowel prep but further research is needed to develop a standardized platform for uniformity.

\section{Competing interests}

None

\section{References}

[1] Cancer Facts and Figures. American Cancer Society; Accessed at: 2017: https://www.cancer.org/research/cancer-facts-statistics/allcancer-facts-figures/cancer-facts-figures-2017.html

[2] Johnson DA, Barkun AN, Cohen LB et al. Optimizing adequacy of bowel cleansing for colonoscopy: recommendations from the US Multi-Society Task Force on Colorectal Cancer. Am J Gastroenterol 2014; 109: $1528-1545$

[3] Froehlich F, Wietlisbach V, Gonvers J] et al. Impact of colonic cleansing on quality and diagnostic yield of colonoscopy: the European Panel of Appropriateness of Gastrointestinal Endoscopy European multicenter study. Gastrointest Endosc 2005; 61: $378-384$

[4] Rex DK, Imperiale TF, Latinovich DR et al. Impact of bowel preparation on efficiency and cost of colonoscopy. Am J Gastroenterol 2002; 97 : $1696-1700$

[5] Harewood GC, Sharma VK, de Garmo P. Impact of colonoscopy preparation quality on detection of suspected colonic neoplasia. Gastrointest Endosc 2003; 58: 76 - 79

[6] Hendry PO, Jenkins JT, Diament RH. The impact of poor bowel preparation on colonoscopy: a prospective single centre study of 10,571 colonoscopies. Colorectal Dis 2007; 9: 745-748

[7] Guo X, Yang Z, Zhao L et al. Enhanced instructions improve the quality of bowel preparation for colonoscopy: a meta-analysis of randomized controlled trials. Gastrointest Endosc 2017; 85: 90 - 97. e96

[8] Tae JW, Lee JC, Hong SJ et al. Impact of patient education with cartoon visual aids on the quality of bowel preparation for colonoscopy. Gastrointest Endosc 2012; 76: 804-811

[9] Lorenzo-Zuniga V, Moreno de Vega V, Marin I et al. Improving the quality of colonoscopy bowel preparation using a smart phone application: a randomized trial. Dig Endosc 2015; 27: 590 - 595
[10] Sharara Al, Chalhoub JM, Beydoun M et al. A customized mobile application in colonoscopy preparation: a randomized controlled trial. Clin Transl Gastroenterol 2017; 8: e211

[11] Back SY, Kim HG, Ahn EM et al. Impact of patient audiovisual re-education via a smartphone on the quality of bowel preparation before colonoscopy: a single-blinded randomized study. Gastrointest Endosc 2018; 87: 789-799.e4

[12] Smartphones in the U.S. - Statistics \& Facts. Statistica; Accessed at: https://www.statista.com/topics/2711/us-smartphone-market/ SitUS-SFAa

[13] Higgins JP. Smartphone applications for patients' health and fitness. Am J Med 2016; 129: 11 - 19

[14] Direito A, Jiang $Y$, Whittaker $R$ et al. Smartphone apps to improve fitness and increase physical activity among young people: protocol of the Apps for IMproving FITness (AIMFIT) randomized controlled trial. BMC Public Health 2015; 15: 635

[15] Cui M, Wu X, Mao J et al. T2DM self-management via smartphone applications: a systematic review and meta-analysis. PLoS One 2016; 11: e0166718

[16] Cho J, Lee S, Shin JA et al. The impact of patient education with a smartphone application on the quality of bowel preparation for screening colonoscopy. Clin Endosc 2017; 50: 479-485

[17] Walter B, Schmid R, von Delius S. A smartphone app for improvement of colonoscopy preparation (ColoprAPP): Development and feasibility study. JMIR Mhealth Uhealth 2017; 5: e138

[18] Kang X, Zhao L, Leung F et al. Delivery of instructions via mobile socia media app increases quality of bowel preparation. Clin Gastroenterol Hepatol 2016; 14: 429-435.e423

[19] Moher D, Shamseer L, Clarke M et al. Preferred reporting items for systematic review and meta-analysis protocols (PRISMA-P) 2015 statement. Syst Rev 2015; 4: 1

[20] Higgins JP, Altman DG, Gotzsche PC et al. The Cochrane Collaboration's tool for assessing risk of bias in randomised trials. BMJ 2011; 343: d5928

[21] Wells G, Shea B, O'Connell D et al. The Newcastle-Ottawa Scale (NOS) for assessing the quality of nonrandomised studies in meta-analyses. Ottawa Hospital; Accessed at: http://www.ohri.ca/programs/clinicaI_epidemiology/oxford.asp

[22] Gurudu SR, Ratuapli S, Heigh R et al. Quality of bowel cleansing for afternoon colonoscopy is influenced by time of administration. Am J Gastroenterol 2010; 105: 2318-2322

[23] Review Manager (RevMan) [Computer program]. Version 5.3. Copenhagen: The Nordic Cochrane Centre TCC; 2014

[24] Johnson DA, Barkun AN, Cohen LB et al. Optimizing adequacy of bowel cleansing for colonoscopy: recommendations from the US multi-society task force on colorectal cancer. Gastroenterology 2014; 147: $903-924$

[25] Sharara Al, Abou Mrad RR. The modern bowel preparation in colonoscopy. Gastroenterol Clin North Am 2013; 42: 577 - 598

[26] Rosenfeld G, Krygier D, Enns RA et al. The impact of patient education on the quality of inpatient bowel preparation for colonoscopy. Can J Gastroenterol 2010; 24: 543-546

[27] Calderwood AH, Lai EJ, Fix OK et al. An endoscopist-blinded, randomized, controlled trial of a simple visual aid to improve bowel preparation for screening colonoscopy. Gastrointest Endosc 2011; 73: 307 314

[28] Prakash SR, Verma S, McGowan J et al. Improving the quality of colonoscopy bowel preparation using an educational video. Can J Gastroenterol 2013; 27: 696 - 700

[29] Spiegel BM, Talley J, Shekelle P et al. Development and validation of a novel patient educational booklet to enhance colonoscopy preparation. Am J Gastroenterol 2011; 106: 875-883 
[30] Liu X, Luo H, Zhang L et al. Telephone-based re-education on the day before colonoscopy improves the quality of bowel preparation and the polyp detection rate: a prospective, colonoscopist-blinded, randomised, controlled study. Gut 2014; 63: 125-130

[31] Park J, Kim TO, Lee NY et al. The effectiveness of short message service to assure the preparation-to-colonoscopy interval before bowel preparation for colonoscopy. Gastroenterol Res Pract 2015; 2015: 628049

[32] Chan WK, Saravanan A, Manikam J et al. Appointment waiting times and education level influence the quality of bowel preparation in adult patients undergoing colonoscopy. BMC Gastroenterol 2011; 11 : 86

[33] Lebwohl B, Wang TC, Neugut Al. Socioeconomic and other predictors of colonoscopy preparation quality. Dig Dis Sci 2010; 55: 2014-2020

[34] Nguyen DL, Wieland M. Risk factors predictive of poor quality preparation during average risk colonoscopy screening: the importance of health literacy. J Gastrointest Liver Dis 2010; 19: 369-372

[35] Basch CH, Hillyer GC, Basch CE et al. Characteristics associated with suboptimal bowel preparation prior to colonoscopy: results of a national survey. Int J Prev Med 2014; 5: 233-237 